\title{
Estimation of epistasis in doubled haploid barley populations considering interactions between all possible marker pairs
}

\author{
Jan Bocianowski
}

Received: 13 March 2013/Accepted: 22 October 2013/Published online: 31 October 2013

(C) The Author(s) 2013. This article is published with open access at Springerlink.com

\begin{abstract}
Epistasis, is the interaction between alleles from two or more loci determining complex traits, and thus plays an important role in the development of quantitative traits of crops. In mapping studies of inbreeding species epistasis is usually defined as the interactions between quantitative trait loci with significant additive gene effects. Indeed, in many studies, genes with small effects do not come into the final model and thus the total epistasis interaction effect is biased. Many loci may not have a significant direct effect on the trait under consideration, but they may still affect trait expression by interacting with other loci. In this paper the benefits of using all loci, not only the loci with significant main effects, for estimation of the epistatic effects are presented. The particular examples are with doubled haploids lines and so are restricted to homozygotes and thus additive genetic effects and additive $\times$ additive interactions. Numerical analyses were carried out on three populations of doubled haploid lines of barley (Hordeum vulgare L.): 120 doubled haploid lines from the Clipper $\times$ Sahara 3771 cross, 145 doubled haploid lines from the Harrington $\times$ TR306 cross and 150 doubled haploid lines from the Steptoe $\times$ Morex cross. In total, 157 sets of observations
\end{abstract}

J. Bocianowski ( $\square)$

Department of Mathematical and Statistical Methods, Poznań University of Life Sciences, Wojska Polskiego 28, 60-637 Poznan, Poland

e-mail: jboc@up.poznan.pl were analyzed and altogether 728 pairs of loci were observed for the three datasets.

Keywords Barley · Doubled haploid lines ·

Epistatic $\cdot$ Regression

\section{Introduction}

In homozygotes, additive-by-additive interactions (QTL-by-QTL interaction, gene-gene interaction or epistasis) can play a very important role in controlling the expression of quantitative traits and are typically defined as statistical deviation from the additive genetic effects. However, information about quantitative trait locus (QTL) epistatic interaction can facilitate marker-assisted selection (MAS) for quantitative traits in breeding programs of different plants, for example QTLs with epistatic effects can be used in methods of MAS. If epistasis is important, then MAS schemes should be designed to exploit it. In the presence of epistasis, MAS generally yields more persistent responses than that based exclusively on additive or additive-dominance model. Neglecting epistasis could result in considerable loss in response, that will become more pronounced in later generations. Tests of epistasis are a powerful tool that developmental biologists use to determine the order of developmental triggers in gene regulation pathways, but such tests are most effective when alleles 
conferring complete loss-of-function of the genes under study are used.

With increasing evidence supporting the claim that epistatic interactions are usually involved in the genetic variation of complex traits (Mao et al. 2006; Tabanao and Bernardo 2007), several complicated mapping models were developed to analyze epistatic effects: expanded composite interval mapping (CIM) to multiple interval mapping (Kao et al. 1999), mixed linear model based CIM (Wang et al. 1999), Bayesian approach (Yang et al. 2007; Yi et al. 2007), and weighted multiple linear regression (Bocianowski 2012c). Jannink and Jansen (2001) suggested mapping QTLs with epistasis between QTLs and backgrounds using one-dimensional genome search.

The importance of epistasis has been suggested in numerous classic quantitative genetics studies (Spickett and Thoday 1966; Falconer 1981; Mather and Jinks 1982; Pooni et al. 1987; da Silva Guimarães et al. 2010). Epistasis as an important genetic basis of complex phenotypes has also been revealed in several recent QTL mapping studies (Li et al. 1997; Yu et al. 1997; Ma et al. 2005; Liu et al. 2011; Rahman et al. 2011; Borràs-Gelonch et al. 2012; Krajewski et al. 2012). However, marker-based analyses for estimation of QTL effects usually assume the absence of epistasis among QTLs (Lander and Botstein 1989; Jansen 1993; Zeng 1994; Bocianowski and Krajewski 2009; Rovaris et al. 2011). This assumption was made largely for simplification of the statistical models. However, acceptance of this assumption may result in biased estimates of the positions and effects of QTLs and lower precision and power for QTL detection.

Currently, epistatic interaction is taken into account in research with regard to its important role in control of quantitative traits (Bocianowski 2008, 2012a, b, c). In mapping studies, epistasis is usually defined as an interaction between QTLs with the assumption that epistatic interaction effects are shown only by loci with significant additive gene action effects. One of the conclusions of a previous simulation study (Bocianowski 2012a) was that the estimate of the total epistatic interaction effect based on the QTLs with significant additive gene action effects was smaller than the effect obtained from traditional quantitative genetics method (based on only phenotypic observations-without marker observations). However, in many mapping cases, when considering inbred lines, genes with small additive effects do not come into the final model and the total epistatic interaction effect is biased. Many loci may not have a significant effect directly on the trait, but they may affect trait expression by interacting with other loci. Hence, the aim of this paper is to estimate epistatic interactions, using inbred lines as an example, between all the loci used in the experiment in comparison to the values when epistatic effects were assessed using only QTLs with significant additive effects.

\section{Materials and methods}

\section{Datasets}

The first dataset included 120 doubled haploid (DH) lines of barley, derived from the cross between the Australian barley variety Clipper and the Algerian landrace Sahara 3771 (CS) at the Waite Agricultural Research Institute, University of Adelaide, Australia (Karakousis et al. 2003). The lines were analyzed with respect to four phenotypic traits: beta-amylase activity (BA), alpha-amylase activity (AA), beta-glucanase activity (BG), and cyst nematode resistance (CCN). Observations of 183 molecular markers (SSR and RFLP) were used in the research.

The second dataset was the barley Harrington $\times$ TR306 $(\mathrm{HT})$ DH population (Tinker et al. 1996), a well-known population from the North American Barley Genome Mapping Project (http:// wheat.pw.usda.gov/ggpages/maps/Hordeum). The data matrix consisted of $145 \mathrm{DH}$ lines. The DH lines were analyzed for seven phenotypic traits (weight of grain harvested per unit area, WG; number of days from planting until emergence of $50 \%$ of heads on main tillers, $\mathrm{NH}$; number of days from planting until physiological maturity, NM; plant height, $\mathrm{H}$; lodging transformed by $\arcsin \sqrt{x / 100}, \mathrm{~L} ; 1,000$ kernel weight, $\mathrm{KW}$; and test weight, TW). The map used in the study was composed of 127 molecular markers (mostly RFLP) with the mean distance between the markers being $10.62 \mathrm{~cm}$. The results shown are observations from five locations (in four locations where the observations were made during 2 years): ON92a-Ailsa Craig, Ontario, 1992; ON93a-Ailsa Craig, Ontario, 1993; ON92b-Elora, Ontario, 1992; ON93b-Elora, Ontario, 1993; MB92-Brandon, 
Manitoba, 1992; MB93-Brandon, Manitoba, 1993; QC93-Ste-Anne-de-Bellevue, Quebec, 1993; SK92a-Outlook, Saskatchewan, 1992; and SK93aOutlook, Saskatchewan, 1992.

The third population dataset included $150 \mathrm{DH}$ lines of barley, obtained from the Steptoe $\times$ Morex $(\mathrm{SM})$ cross, used in the North American Barley Genome Mapping project and tested in sixteen environments (Kleinhofs et al. 1993; Romagosa et al. 1996; http:// wheat.pw.usda.gov/ggpages/SxM). The linkage map used consisted of 223 molecular markers, mostly RFLP, with a mean distance between markers of $5.66 \mathrm{cM}$. The DH lines were analyzed for eight phenotypic traits (alpha amylase, AA; diastatic power, DP; grain protein, GP; grain yield, GY; height, H; heading date, HD; lodging, L; and malt extract, ME) (Hayes et al. 1993). Grain protein, lodging and malt extract were transformed by $\arcsin \sqrt{x / 100}$.

Missing marker data in all the three datasets were estimated by the method of Martinez and Curnow (1994), that is, with the use of non-missing data of flanking markers.

\section{Genetic model}

Estimation of additive $\times$ additive epistatic interactions $(a a)$ was based on the assumption that the genes responsible for the trait were closely linked to observed molecular marker (Bocianowski 2012b). A two-stage algorithm was employed for the selection of significant pairs of loci (markers) with significant epistasis interaction effects.

In the first step of the selection, a fixed linear model for the simultaneous search for two interacting loci ( $m_{l_{i}}$ and $m_{l_{j}}, i, j=1,2, \ldots, p ; l_{1}, l_{2}, \ldots, l_{p} \in\{1,2, \ldots, q\}$, where $p$ denotes the number of selected loci, $q$ is the number of loci) can be expressed as follows:

$y_{k}=\mu+a_{l_{i}} m_{l_{i} k}+a_{l_{j}} m_{l_{j} k}+a a_{l_{i} l_{j}} m_{l_{i} k} m_{l_{j} k}+\varepsilon_{k}$,

where $y_{k}$ is the phenotypic value of a quantitative trait measured on the $k$-th individual $(k=1,2, \ldots, n), \mu$ is the population mean, $a_{l_{i}}$ and $a_{l_{j}}$ are the additive effects (fixed) of the two loci $\left(m_{l_{i}}\right.$ and $\left.m_{l_{i}}\right)$, respectively, $a a_{l_{i} l_{j}}$ is the epistatic interaction effect (fixed) between $m_{l_{i}}$ and $m_{l_{j}}, m_{l_{i k}}$ and $m_{l_{j k}}$ are observations of the $i$-th and $j$-th loci of the $k$-th individual, and $\varepsilon_{k} \sim N\left(0, \sigma^{2}\right)$ is the random residual effect.

Model (1) can be written as a matrix form of the fixed linear model:

$y=X \beta+\varepsilon$,

where $\boldsymbol{y}$ is an $n$-dimensional vector of phenotypic values, $\boldsymbol{X}$ is known incidence matrix, $\beta=\left(\mu, a_{l_{i}}, a_{l_{j}}\right.$, $\left.a a_{l_{i} l_{j}}\right)^{T}$ is a 4-vector of fixed effects, and $\varepsilon \sim N\left(0, \sigma^{2} I\right)$ is an $n$-vector of random residuals.

Marker pairs selected in the first step were subjected to backward stepwise selection in the second stage. The final model is as follows:

$$
\begin{aligned}
y_{k}= & \mu+\sum_{t=1}^{p} a_{l_{t}} m_{l_{t k}} \\
& +\sum_{t=1}^{p-1} \sum_{\substack{t^{\prime}=t+1 \\
t^{\prime} \neq t}}^{p} a a_{l_{l^{\prime}}} m_{l_{l_{k}}} m_{l_{t^{\prime} k}}+\varepsilon_{k},
\end{aligned}
$$

where $l_{t}, l_{t^{\prime}} \in\{1,2, \ldots, q\}$. In the second step the critical significance level amounting to 0.001 , resulting from the Bonferroni correction (Province 1999), was used. The Bonferroni correction is a method used to counteract the problem of multiple comparisons. It is considered the simplest and most conservative method to control type I errors for multiple tests. If total number of all epistatic pairs is equal to 50, than the global significance level needed to be adjusted to $\alpha=0.05 / 50=0.001$.

The total epistatic interaction effect of gene pairs influencing the trait, defined as the sum of values of individual pairs' effects from model (2), can be found as:

$\widehat{a a}=\sum_{t=1}^{p-1} \sum_{\substack{t^{\prime}=t+1 \\ t^{\prime} \neq t}}^{p} \widehat{a a}_{l_{t} l_{t^{\prime}}}$.

The coefficients of determination were used to measure how the models (1) and (2), respectively, fitted the data and, in this study, were the amount of the phenotypic variance explained by individual pairs of interactive markers $\left(R_{i}^{2}\right)$ and by total pairs of interactive markers $\left(R_{T}^{2}\right)$.

Analyses of the data were performed using the statistical package GenStat v. 10.1 (GenStat 2007). 
Table 1 Number of epistatic interaction pairs (No.), the total epistatic interaction effect $(a a)$, difference between $a a$ and epistatic effects assessed using only QTLs $\left(a a-a a_{g}\right)$, percentage of variation explained by individual pairs $\left(R_{i}^{2}\right)$ and total percentage of variation explained by all pairs $-R_{T}^{2}$ for $120 \mathrm{DH}$ lines of barley from the Clipper $\times$ Sahara 3771 cross

\begin{tabular}{lllll}
\hline Parameters & \multicolumn{4}{l}{ Trait } \\
\cline { 2 - 5 } & BA & AA & BG & CCN \\
\hline No. & 3 & 7 & 9 & 12 \\
$a a$ & -367.2 & -67.82 & 69.89 & 27.13 \\
$a a-a a_{g}^{\mathrm{a}}$ & -457.3 & -45.82 & 69.89 & 25.75 \\
$R_{i}^{2}$ & $20.2-23.2$ & $16.7-21.1$ & $16.7-23.9$ & $6.7-11.4$ \\
$R_{T}^{2}$ & 44.2 & 51.0 & 62.9 & 44.4 \\
\hline
\end{tabular}

$B A$ beta-amylase activity, $A A$ alpha-amylase activity, $B G$ betaglucanase activity, $C N R$ cyst nematode resistance

a $a a_{g}$ values from previous studies (Bocianowski 2008)

\section{Results}

A total of 31 pairs of loci with epistatic effects were detected for CS mapping population (Table 1), 194 pairs for HT population (Table 2) and 503 pairs in SM population (Table 3). The observed epistatic total effects of loci pairs were: negative in 40 cases, while positive in 23 cases, for the HT population (Table 2), negative in 34 cases $(37.78 \%$ ), while positive in 56 cases for SM population (Table 3). For individual traits the sign of the epistatic effect depended on the environment. The percentage of phenotypic variation explained by an individual pair of loci $\left(R_{i}^{2}\right)$ ranged from 6.7 to $23.9 \%$ for the CS population (Table 1), from 6.7 to $11.5 \%$ for the HT population (Table 2) and from 6.5 to $14.9 \%$ for the SM population (Table 3). The total percentage of phenotypic variation explained by all the pairs of epistatic loci together $\left(R_{T}^{2}\right)$ ranged from 44.2 to $62.9 \%$ for the CS population (Table 1), from 6.7 to $48.5 \%$ for the HT population (Table 2) and from 6.9 to $93.2 \%$ for the SM population (Table 3 ). For the CS population the loci pair CDO105-BCD135 influenced two phenotypic traits: AA and BG. Therefore, CDO105-BCD135 might be a pleiotropic pair of loci or very tight linkage. Additionally, in the Tables 1, 2 and 3 are presented differences between epistatic effects assessed using all loci ( $a a)$ and epistatic effects assessed using only loci with significant additive effects $\left(a a_{g}\right)$, it should be noted that the $a a_{g}$ values have been presented in previous studies (Bocianowski 2008, 2012b).

\section{Discussion}

The genetic variation in continuous traits is usually governed by a polygenic network system, composed of many genes with small effect, and sometimes including one or a few genes with large effect. Loci with minor or no individual effect can also be involved in epistatic interaction. The statistical power to detect pairwise epistatic interactions is lower than for the main QTL because the tests of significance must be conducted for two intervals rather than just one, and consequently a higher critical threshold per test must be applied to overcome the problem of multiple tests (Melchinger et al. 2007). This can be translated into small-effect interactions that would remain undetected unless a large number of individuals are considered. Quantitative traits are determined by many genes with small effects. In this paper the epistatic effects were estimated as an interaction between all pairs of loci. In total, 728 pairs of loci were found for the three datasets. The very important and difficult problem is the size of the population for estimating of epistasis effect based on the model with a huge amount of effects. The larger power of detection of pairwise epistatic interactions would be the result of use of larger mapping population. Additionally, for a larger mapping population we can obtain greater precision of estimate, which can be a positive implication in plant breeding.

More epistatic pairs were obtained for all the four cases of the DH lines from the CS population than in the previous paper (Bocianowski 2008), in which epistatic effects were considered as interactions between loci with significant additive effects. After the analysis of the HT DH lines in the four cases (NM in MB92, $\mathrm{H}$ in ON93a, L in ON92a and L in ON92b), epistatic effects showed only loci with significant additive effects-differences $a a-a a_{g}$ equal to 0 (compared with results presented by Bocianowski 2012b). In 38 cases, the epistatic effects calculated as locus $\times$ locus interactions were non-significant (see Bocianowski 2012b). In this paper, those effects were statistically significant different $a a-a a_{g}=a a$ (Table 2). In two cases (AA in MTi91 and ME in WA92) for the SM DH lines, the epistatic effects had 
Table 2 Number of epistatic interaction pairs (No.), the total epistatic interaction effect $(a a)$, difference between $a a$ and epistatic effects assessed using only QTLs $\left(a a-a a_{g}\right)$, percentage of variation explained by individual pairs $\left(R_{i}^{2}\right)$ and total percentage of variation explained by all pairs $-R_{T}^{2}$ for doubled haploid lines from Harrington $\times$ TR306 cross

\begin{tabular}{|c|c|c|c|c|c|c|c|}
\hline \multirow[t]{2}{*}{ Parameters } & \multicolumn{7}{|l|}{ Trait } \\
\hline & WG & $\mathrm{NH}$ & NM & $\mathrm{H}$ & $\mathrm{L}$ & KW & TW \\
\hline \multicolumn{8}{|l|}{ ON93a } \\
\hline No. & 5 & 2 & 2 & 1 & 1 & 1 & 2 \\
\hline$a a$ & -12.7 & 0.688 & -0.637 & -1.662 & -0.074 & -1.485 & -0.071 \\
\hline$a a-a a_{g}^{\mathrm{a}}$ & -12.08 & 0.688 & -0.664 & -4.092 & 0 & -1.485 & -0.071 \\
\hline$R_{i}^{2}$ & $6.8-9.6$ & $6.9-6.9$ & $6.9-8.3$ & 6.8 & 6.8 & 7.9 & $6.7-8.4$ \\
\hline$R_{T}^{2}$ & 38.4 & 12.8 & 14.7 & 6.8 & 6.8 & 7.9 & 14.2 \\
\hline \multicolumn{8}{|l|}{ ON93a } \\
\hline No. & 3 & 6 & 2 & 1 & 1 & 3 & 4 \\
\hline$a a$ & -36.53 & -0.618 & -0.004 & -0.625 & 0.064 & 3.103 & -2.459 \\
\hline$a a-a a_{g}$ & -36.53 & -0.618 & 0.102 & 0 & 0.064 & 3.103 & -2.249 \\
\hline$R_{i}^{2}$ & $7.5-9.5$ & $7.0-9.3$ & $6.7-7.2$ & 7.3 & 7.0 & $6.8-7.5$ & $6.7-7.3$ \\
\hline$R_{T}^{2}$ & 24.7 & 47.4 & 12.7 & 7.3 & 7.0 & 21.2 & 28.1 \\
\hline \multicolumn{8}{|l|}{ ON92b } \\
\hline No. & 4 & 5 & 3 & 2 & 1 & 1 & 3 \\
\hline$a a$ & -0.28 & 0.352 & 0.21 & 0.45 & 0.045 & -0.88 & 0.836 \\
\hline$a a-a a_{g}$ & -7.718 & 0.276 & 0.21 & 0.45 & 0 & -0.88 & 0.538 \\
\hline$R_{i}^{2}$ & $7.1-8.5$ & $7.7-9.4$ & $7.5-8.1$ & $7.0-9.6$ & 6.7 & 7.7 & $6.8-9.3$ \\
\hline$R_{T}^{2}$ & 31.2 & 41.6 & 23.1 & 15.7 & 6.7 & 7.7 & 23.9 \\
\hline \multicolumn{8}{|l|}{ ON93b } \\
\hline No. & 5 & 3 & 3 & 3 & 5 & 2 & 3 \\
\hline$a a$ & 11.29 & -0.403 & -0.144 & 0.829 & 0.153 & -2.505 & 0.978 \\
\hline$a a-a a_{g}$ & 6.31 & -0.403 & -0.144 & 1.257 & 0.091 & -2.505 & 0.480 \\
\hline$R_{i}^{2}$ & $6.8-10.4$ & $6.8-7.0$ & $7.0-8.1$ & $8.0-9.2$ & $6.8-11.5$ & $9.0-9.1$ & $7.3-9.8$ \\
\hline$R_{T}^{2}$ & 38.6 & 20.7 & 23.1 & 25.2 & 44.3 & 16.6 & 25.4 \\
\hline \multicolumn{8}{|l|}{ MB92 } \\
\hline No. & 2 & 2 & 1 & 3 & 4 & 3 & 5 \\
\hline$a a$ & 28.9 & -0.008 & -0.079 & -1.013 & 0.082 & -0.871 & -1.675 \\
\hline$a a-a a_{g}$ & 28.9 & 0.166 & 0 & -1.013 & 0.082 & -0.922 & -1.675 \\
\hline$R_{i}^{2}$ & $6.7-7.2$ & $8.4-8.8$ & 6.9 & $7.1-10.9$ & $7.1-8.7$ & $6.7-8.9$ & $7.1-8.2$ \\
\hline$R_{T}^{2}$ & 13.4 & 16.1 & 6.9 & 25.6 & 30.3 & 22.6 & 38.2 \\
\hline \multicolumn{8}{|l|}{ MB93 } \\
\hline No. & 4 & 3 & 5 & 5 & 3 & 3 & 3 \\
\hline$a a$ & 38.11 & -0.567 & 0.463 & 1.228 & -0.05 & -1.013 & -0.731 \\
\hline$a a-a a_{g}$ & 38.11 & -0.776 & 0.463 & 1.325 & -0.047 & -1.013 & -0.306 \\
\hline$R_{i}^{2}$ & $7.1-10.1$ & $6.8-8.0$ & $6.7-8.3$ & $6.7-7.6$ & $7.6-9.7$ & $7.7-9.1$ & $7.0-9.5$ \\
\hline$R_{T}^{2}$ & 31.4 & 21.9 & 38.4 & 36.4 & 25.2 & 25.6 & 24.9 \\
\hline \multicolumn{8}{|l|}{ QC93 } \\
\hline No. & 3 & 5 & 3 & 6 & 4 & 3 & 3 \\
\hline$a a$ & -7.89 & -0.51 & -0.475 & 2.17 & -0.151 & 0.924 & -1.243 \\
\hline$a a-a a_{g}$ & -7.88 & -0.237 & -0.222 & 2.17 & -0.151 & 0.924 & -1.243 \\
\hline$R_{i}^{2}$ & $6.9-9.6$ & $7.0-10.7$ & $7.1-10.0$ & $6.9-10.8$ & $6.9-8.6$ & $7.6-9.0$ & $7.8-8.9$ \\
\hline$R_{T}^{2}$ & 23.9 & 43.6 & 25.6 & 48.5 & 31.7 & 24.9 & 24.8 \\
\hline
\end{tabular}


Table 2 continued

\begin{tabular}{|c|c|c|c|c|c|c|c|}
\hline \multirow[t]{2}{*}{ Parameters } & \multicolumn{7}{|l|}{ Trait } \\
\hline & WG & $\mathrm{NH}$ & NM & $\mathrm{H}$ & $\mathrm{L}$ & KW & TW \\
\hline \multicolumn{8}{|l|}{ SK92a } \\
\hline No. & 1 & 2 & 3 & 4 & 5 & 2 & 4 \\
\hline$a a$ & 31.7 & -1.257 & -2.044 & -0.182 & -0.104 & -0.072 & -0.107 \\
\hline$a a-a a_{g}$ & 31.7 & -1.257 & -2.044 & -0.182 & -0.104 & -0.072 & -0.107 \\
\hline$R_{i}^{2}$ & 7.6 & $7.4-7.5$ & $7.3-8.6$ & $6.9-10.2$ & $6.7-10.7$ & $7.2-7.3$ & $7.9-10.0$ \\
\hline$R_{T}^{2}$ & 7.6 & 14.1 & 23.7 & 31.3 & 39.5 & 14.5 & 34.0 \\
\hline \multicolumn{8}{|l|}{ SK93a } \\
\hline No. & 2 & 3 & 3 & 1 & 5 & 5 & 4 \\
\hline$a a$ & 0.31 & -0.448 & -0.492 & -1.02 & -0.065 & 1.052 & 1.422 \\
\hline$a a-a a_{g}$ & 0.31 & -0.448 & -0.492 & -1.02 & -0.112 & 0.503 & 1.422 \\
\hline$R_{i}^{2}$ & $6.8-7.1$ & $7.1-10.7$ & $6.8-8.7$ & 8.3 & $6.9-10.4$ & $6.8-8.2$ & $6.7-7.8$ \\
\hline$R_{T}^{2}$ & 12.8 & 27.6 & 22.7 & 8.3 & 41.0 & 36.9 & 28.4 \\
\hline
\end{tabular}

ON92a Ailsa Craig, Ontario, 1992; ON93a Ailsa Craig, Ontario, 1993; ON92b Elora, Ontario, 1992; ON93b Elora, Ontario, 1993; MB92 Brandon, Manitoba, 1992; MB93 Brandon, Manitoba, 1993; QC93 Ste-Anne-de-Bellevue, Quebec, 1993; SK92a Outlook, Saskatchewan, 1992; SK93a Outlook, Saskatchewan, 1992; WG weight of grain harvested per unit area; $N H$ number of days from planting until emergence of $50 \%$ of heads on main tillers; $N M$ number of days from planting until physiological maturity; $H$ plant height; $L$ lodging; $K W$ 1,000 kernel weight; $T W$ test weight

a $a a_{g}$ values from previous studies (Bocianowski 2012b)

the same values as were reported by Bocianowski (2012b) $\left(a a-a a_{g}=0\right.$, Table 3). In most cases an improvement in estimates of epistatic interaction effects was observed in relation to the results obtained with the assumption that epistatic effects are only relevant between loci with significant additive genetic effects. This improvement was expressed as: (1) significant epistatic effects in the cases when they were absent for markers with additive effects $(a a-$ $\left.a a_{g}=a a\right)$; (2) estimates of epistatic effects closer to those obtained by the traditional quantitative genetics method based on only phenotypic observationswithout marker observations (see Bocianowski 2012a, b) in providing results which are closer to the true (unknown) value.

Interactions between loci with non-significant main-effects were obtained by Ma et al. (2007), Imtiaz et al. (2008) and Peng et al. (2011), while Charmet et al. (1999) considered situations when at least one of the interactive QTLs had an additive effect. Bocianowski (2013) investigated the effect of consideration/ non-consideration of the epistatic effects on the additive gene action effects. Comparison of the assessment of the estimated additive gene action effects, based on the model without epistasis, with that resulting from the model taking into consideration the epistasis effect, was made. The results obtained showed the advantages of including the interactions by giving an improvement in accuracy in predicting the genotypic value of the progenies.

The proposed method of estimation of epistasis as an interactions between all pairs of loci is more effective than the method using only QTLs with significant additive effects. Estimation of additive $\times$ additive interaction epistatic effects on the basis of model presented by Bocianowski (2012a, b), using only selected genes-with significant main effects, can be biased. The estimator of epistasis effects based on method proposed in this paper is unbiased because the model contains all potential pairs of loci which determine the quantitative trait.

Quantitative trait locus-analysis tools are useful for the analysis of complex traits in $\mathrm{DH}$ populations and for identification of favorable alleles in diverse germplasm. Characterization of the determinants of economically important phenotypes showing complex inheritance (by estimation of genetic parameters in an additive and additive-by-additive epistasis interaction model) should lead to more effective use of genetic resources. So, by way of illustration, a 
Table 3 Number of epistatic interaction pairs (No.), the total epistatic interaction effect ( $a a$ ) and difference between $a a$ and epistatic effects assessed using only QTLs $\left(a a-a a_{g}\right)$, percentage of variation explained by individual pairs $\left(R_{i}^{2}\right)$ and total percentage of variation explained by all pairs $-R_{T}^{2}$ for doubled haploid lines from Steptoe $\times$ Morex doubled haploid lines barley population

\begin{tabular}{|c|c|c|c|c|c|c|c|c|}
\hline \multirow[t]{2}{*}{ Paramters } & \multicolumn{8}{|l|}{ Trait } \\
\hline & $\mathrm{AA}$ & DP & GY & GP & HD & $\mathrm{H}$ & $\mathrm{L}$ & $\mathrm{ME}$ \\
\hline \multicolumn{9}{|l|}{ ID91 } \\
\hline No. & 8 & 3 & 4 & 3 & 5 & 4 & - & 8 \\
\hline$a a$ & 6.732 & 14.81 & -0.798 & 0.0035 & 1.038 & 0.356 & - & -0.0099 \\
\hline$a a-a a_{g}^{\mathrm{a}}$ & 5.590 & 13.488 & -0.962 & 0.0035 & 0.997 & 1.539 & - & -0.0079 \\
\hline$R_{i}^{2}$ & $6.6-9.2$ & $6.5-7.4$ & $7.1-10.0$ & $6.7-7.6$ & $6.7-7.6$ & $6.6-10.4$ & - & $6.5-10.5$ \\
\hline$R_{T}^{2}$ & 61.0 & 20.5 & 33.2 & 21.2 & 34.9 & 31.4 & - & 63.1 \\
\hline \multicolumn{9}{|l|}{ ID92 } \\
\hline No. & 8 & 7 & 6 & 6 & 6 & 5 & - & 8 \\
\hline$a a$ & 5.21 & -6.29 & 1.578 & -0.0098 & 0.155 & 8.633 & - & 0.0092 \\
\hline$a a-a a_{g}$ & 3.987 & -0.287 & 1.447 & -0.0088 & -0.227 & 10.089 & - & 0.0092 \\
\hline$R_{i}^{2}$ & $6.6-8.6$ & $6.9-10.1$ & $6.8-11.2$ & $6.6-10.6$ & $6.5-8.6$ & $7.8-9.5$ & - & $6.5-10.2$ \\
\hline$R_{T}^{2}$ & 59.6 & 58.9 & 50.9 & 47.1 & 44.2 & 41.1 & - & 61.2 \\
\hline \multicolumn{9}{|l|}{ MA92 } \\
\hline No. & - & - & 4 & - & 5 & 4 & 5 & - \\
\hline$a a$ & - & - & -0.007 & - & 1.371 & 6.670 & -0.093 & - \\
\hline$a a-a a_{g}$ & - & - & 0.013 & - & 0.936 & 6.682 & -0.116 & - \\
\hline$R_{i}^{2}$ & - & - & $6.9-7.2$ & - & $6.6-8.1$ & $6.6-10.7$ & $6.6-12.7$ & - \\
\hline$R_{T}^{2}$ & - & - & 28.4 & - & 37.2 & 31.2 & 65.8 & - \\
\hline \multicolumn{9}{|l|}{ MN92 } \\
\hline No. & 2 & 5 & 11 & 6 & 6 & 2 & - & 6 \\
\hline$a a$ & 2.927 & 5.550 & 1.050 & 0.0007 & 0.043 & 0.3 & - & 0.0003 \\
\hline$a a-a a_{g}$ & 4.363 & 18.483 & 0.924 & 0.0007 & 0.043 & 0.3 & - & -0.0007 \\
\hline$R_{i}^{2}$ & $6.7-8.7$ & $6.5-10.1$ & $6.5-9.1$ & $6.5-9.1$ & $6.5-10.5$ & $8.8-11.8$ & - & $6.8-8.3$ \\
\hline$R_{T}^{2}$ & 14.6 & 38.4 & 82.9 & 44.8 & 48.8 & 19.4 & - & 45.7 \\
\hline \multicolumn{9}{|l|}{ MTd91 } \\
\hline No. & - & - & 7 & - & 8 & 8 & - & - \\
\hline$a a$ & - & - & -0.268 & - & 3.979 & -3.197 & - & - \\
\hline$a a-a a_{g}$ & - & - & -0.047 & - & 3.355 & -3.197 & - & - \\
\hline$R_{i}^{2}$ & - & - & $6.8-9.7$ & - & $6.7-8.7$ & $6.6-8.7$ & - & - \\
\hline$R_{T}^{2}$ & - & - & 54.8 & - & 59.3 & 60.3 & - & - \\
\hline \multicolumn{9}{|l|}{ MTd92 } \\
\hline No. & 4 & 3 & 8 & 6 & 3 & 6 & 7 & 4 \\
\hline$a a$ & 2.514 & 21.13 & -0.468 & -0.0075 & 1.267 & 7.809 & -0.232 & -0.0117 \\
\hline$a a-a a_{g}$ & 1.773 & 12.286 & -0.418 & -0.0075 & 1.267 & 5.326 & -0.263 & -0.0127 \\
\hline$R_{i}^{2}$ & $6.6-7.7$ & $7.0-8.5$ & $6.5-8.9$ & $6.9-9.6$ & $7.4-9.2$ & $6.7-14.9$ & $6.5-7.6$ & $7.0-8.5$ \\
\hline$R_{T}^{2}$ & 28.3 & 23.0 & 58.5 & 47.0 & 25.5 & 55.0 & 50.5 & 32.3 \\
\hline \multicolumn{9}{|l|}{ MTi91 } \\
\hline No. & 1 & 4 & 6 & 11 & 7 & 8 & - & 7 \\
\hline$a a$ & 0.899 & 9.01 & 0.724 & 0.0264 & -1.081 & 0.407 & - & 0.0144 \\
\hline$a a-a a_{g}$ & 0 & 19.8 & 0.528 & 0.0274 & -1.597 & 1.322 & - & 0.0144 \\
\hline$R_{i}^{2}$ & 8.2 & $6.6-7.8$ & $6.6-8.4$ & $6.5-11.9$ & $6.9-8.7$ & $6.5-8.5$ & - & $6.5-9.2$ \\
\hline
\end{tabular}


Table 3 continued

\begin{tabular}{|c|c|c|c|c|c|c|c|c|}
\hline \multirow[t]{2}{*}{ Paramters } & \multicolumn{8}{|l|}{ Trait } \\
\hline & AA & $\mathrm{DP}$ & GY & GP & HD & $\mathrm{H}$ & $\mathrm{L}$ & $\mathrm{ME}$ \\
\hline$R_{T}^{2}$ & 8.2 & 28.5 & 45.2 & 87.8 & 52.2 & 57.7 & - & 51.5 \\
\hline \multicolumn{9}{|l|}{ MTi92 } \\
\hline No. & 7 & 4 & 4 & 6 & 4 & 5 & 6 & 4 \\
\hline$a a$ & 1.432 & 12.72 & 0.961 & 0.0167 & 1.522 & -3.187 & 0.207 & 0.0113 \\
\hline$a a-a a_{g}$ & 0.986 & 4.742 & -0.961 & 0.0257 & 1.259 & -2.108 & 0.151 & 0.0113 \\
\hline$R_{i}^{2}$ & $6.8-9.1$ & $6.9-13.7$ & $6.6-12.3$ & $6.5-7.5$ & $7.1-7.9$ & $7.3-9.7$ & $6.8-8.9$ & $7.3-9.1$ \\
\hline$R_{T}^{2}$ & 54.3 & 36.7 & 35.0 & 41.5 & 30.0 & 41.1 & 46.6 & 34.0 \\
\hline \multicolumn{9}{|l|}{ NY92 } \\
\hline No. & - & - & 7 & - & 6 & 5 & 5 & - \\
\hline$a a$ & - & - & 0.269 & - & 4.934 & 13.053 & 0.253 & - \\
\hline$a a-a a_{g}$ & - & - & 0.269 & - & 4.749 & 12.396 & 0.279 & - \\
\hline$R_{i}^{2}$ & - & - & $6.5-11.6$ & - & $6.7-11.0$ & $6.6-9.2$ & $7.4-10.9$ & - \\
\hline$R_{T}^{2}$ & - & - & 58.0 & - & 49.9 & 39.5 & 44.6 & - \\
\hline \multicolumn{9}{|l|}{ ON92 } \\
\hline No. & - & - & 9 & - & 11 & 4 & 4 & - \\
\hline$a a$ & - & - & -0.190 & - & 0.384 & -0.196 & 0.539 & - \\
\hline$a a-a a_{g}$ & - & - & -0.288 & - & 2.370 & -0.196 & 0.539 & - \\
\hline$R_{i}^{2}$ & - & - & $6.6-9.1$ & - & $6.5-14.4$ & $6.5-8.9$ & $6.5-13.9$ & - \\
\hline$R_{T}^{2}$ & - & - & 69.1 & - & 93.2 & 29.6 & 36.3 & - \\
\hline \multicolumn{9}{|l|}{ OR91 } \\
\hline No. & 9 & 2 & 7 & 5 & 7 & 4 & - & 5 \\
\hline$a a$ & -0.979 & 13.84 & -0.282 & 0.0151 & 0.856 & -0.596 & - & -0.0059 \\
\hline$a a-a a_{g}$ & -1.665 & 0.350 & -0.282 & 0.0151 & 0.614 & -0.596 & - & -0.0059 \\
\hline$R_{i}^{2}$ & $6.6-9.5$ & $6.7-7.0$ & $6.5-8.7$ & $6.6-8.2$ & $6.5-10.1$ & $6.6-8.9$ & - & $7.1-12.0$ \\
\hline$R_{T}^{2}$ & 72.0 & 12.7 & 51.6 & 36.6 & 56.7 & 29.6 & - & 44.8 \\
\hline \multicolumn{9}{|l|}{ SKg92 } \\
\hline No. & - & - & 8 & - & 6 & 5 & - & - \\
\hline$a a$ & - & - & -0.813 & - & -0.302 & -4.093 & - & - \\
\hline$a a-a a_{g}$ & - & - & -1.092 & - & -0.302 & -9.754 & - & - \\
\hline$R_{i}^{2}$ & - & - & $6.6-11.1$ & - & $6.6-12.3$ & $7.4-10.4$ & - & - \\
\hline$R_{T}^{2}$ & - & - & 65.8 & - & 50.2 & 44.5 & - & - \\
\hline \multicolumn{9}{|l|}{ SKg93 } \\
\hline No. & - & - & 6 & - & 4 & 3 & - & - \\
\hline$a a$ & - & - & 0.258 & - & 0.110 & 3.255 & - & - \\
\hline$a a-a a_{g}$ & - & - & 0.085 & - & -0.252 & 3.255 & - & - \\
\hline$R_{i}^{2}$ & - & - & $6.9-7.7$ & - & $6.5-10.3$ & $7.0-9.4$ & - & - \\
\hline$R_{T}^{2}$ & - & - & 43.7 & - & 31.2 & 23.9 & - & - \\
\hline \multicolumn{9}{|l|}{ SKo92 } \\
\hline No. & - & - & 3 & - & 4 & 7 & 5 & - \\
\hline$a a$ & - & - & -0.285 & - & -2.554 & -2.292 & -0.084 & - \\
\hline$a a-a a_{g}$ & - & - & -0.285 & - & -1.799 & -2.292 & -0.127 & - \\
\hline$R_{i}^{2}$ & - & - & $6.8-8.7$ & - & $7.2-8.3$ & $6.6-10.4$ & $7.1-7.8$ & - \\
\hline$R_{T}^{2}$ & - & - & 23.0 & - & 30.4 & 55.1 & 36.5 & - \\
\hline
\end{tabular}


Table 3 continued

\begin{tabular}{|c|c|c|c|c|c|c|c|c|}
\hline \multirow[t]{2}{*}{ Paramters } & \multicolumn{8}{|l|}{ Trait } \\
\hline & $\mathrm{AA}$ & DP & GY & GP & HD & $\mathrm{H}$ & $\mathrm{L}$ & $\mathrm{ME}$ \\
\hline \multicolumn{9}{|l|}{ WA91 } \\
\hline No. & 3 & 4 & 5 & 3 & 7 & 6 & - & 10 \\
\hline$a a$ & -2.062 & -9.78 & 0.321 & -0.0054 & 1.052 & -0.641 & - & -0.0099 \\
\hline$a a-a a_{g}$ & -2.062 & -9.78 & 0.322 & -0.0064 & 1.052 & -1.624 & - & -0.0099 \\
\hline$R_{i}^{2}$ & $6.9-8.7$ & $6.5-12.1$ & $6.5-8.7$ & $9.0-10.8$ & $6.6-8.8$ & $7.2-10.1$ & - & $6.6-9.0$ \\
\hline$R_{T}^{2}$ & 24.2 & 33.9 & 35.3 & 28.9 & 53.6 & 49.0 & - & 72.9 \\
\hline \multicolumn{9}{|l|}{ WA92 } \\
\hline No. & 10 & 3 & 7 & 5 & 7 & 6 & - & 1 \\
\hline$a a$ & 6.445 & 5.01 & -0.48 & 0.0062 & 1.103 & 0.316 & - & -0.0018 \\
\hline$a a-a a_{g}$ & 6.039 & -4.439 & -0.313 & 0.0062 & 0.819 & 1.134 & - & 0 \\
\hline$R_{i}^{2}$ & $6.6-11.1$ & $6.7-7.8$ & $6.5-9.0$ & $6.7-10.4$ & $6.6-9.1$ & $6.5-8.4$ & - & 6.9 \\
\hline$R_{T}^{2}$ & 78.4 & 22.0 & 54.9 & 39.2 & 52.5 & 44.2 & - & 6.9 \\
\hline
\end{tabular}

ID91 Aberdeen, Idaho, 1991; ID92 Tetonia, Idaho, 1992; MA92 Brandon, Manitoba, 1992; MN92 Crookston, Minnesota, 1992; MTd91 Bozeman, Montana, dry, 1991; MTd92 Bonzeman, Montana, dry, 1992; MTi91 Bozeman, Montana, irrigated, 1991 ; MTi92 Bozeman, Montana, irrigated, 1992; NY92 Ithaca, New York, 1992; ON92 Guelph, Ontario, 1992; OR91 Klamath Falls, Oregon, 1991; Kg92 Goodlae, Saskatchewan, 1992; SKg93 Kcfr, Saskatchewan, 1992; SKo92 Outlook, Saskatchewan, 1992; WA91 Pullman, Washington, 1991; WA92 Pullman, Washington, 1992; $A A$ alpha amylase; DP diastatic power; GP grain protein; $G Y$ grain yield; $H$ height; $H D$ heading date; $L$ lodging; $M E$ malt extract

a $a a_{g}$ values from previous studies (Bocianowski 2012b)

positive (negative) epistatic effects of additive-byadditive interactions $\left(a a_{i j}\right)$ suggests that the two epistatic loci with homozygous alleles from the same parent $\left(\mathrm{Q}_{i} \mathrm{Q}_{\mathrm{i}} \mathrm{Q}_{\mathrm{j}} \mathrm{Q}_{\mathrm{j}}\right.$ or $\left.\mathrm{q}_{\mathrm{i}} \mathrm{q}_{\mathrm{i}} \mathrm{q}_{j} \mathrm{q}_{\mathrm{j}}\right)$ would increase (decrease) the trait value, otherwise $\mathrm{Q}_{i} \mathrm{Q}_{i} \mathrm{q}_{j} \mathrm{q}_{j}$ or $\mathrm{q}_{\mathrm{i}} \mathrm{q}_{\mathrm{i}} \mathrm{Q}_{\mathrm{j}} \mathrm{Q}_{\mathrm{j}}$ could decrease (increase) the phenotype. Thus the "favorable" allele is a relative concept because of epistasis. A "favorable" allele with positive additive effects may become "unfavorable" following transfer into a new variety due to large negative additive-by-additive effects in the new genetic background. Therefore, not only the QTLs with additive effects should be considered in selection programs, but also additive-by-additive epistatic effects among these QTLs and others. In this paper the epistatic effects have different signs in the individual environments. Hence, this opens the potential for research on an issue that could be very important in breeding programs.

The results obtained indicate that many loci with epistatic effects might not have significant direct effects for quantitative trait in their own right but might affect its expression by their epistatic effects with the other loci.
Open Access This article is distributed under the terms of the Creative Commons Attribution License which permits any use, distribution, and reproduction in any medium, provided the original author(s) and the source are credited.

\section{References}

Bocianowski J (2008) Comparison of two methods of estimation of nonallelic interaction of QTL effects on the basis of doubled haploid lines in barley. Agric Conspectus Scientificus 73(3): 183-187

Bocianowski J (2012a) A comparison of two methods to estimate additive-by-additive interaction of QTL effects by a simulation study. J Theor Biol 308:20-24

Bocianowski J (2012b) Analytical and numerical comparisons of two methods of estimation of additive $\times$ additive interaction of QTL effects. Scientia Agricola 69(4):240-246

Bocianowski J (2012c) The use of weighted multiple linear regression to estimate QTL-by-QTL epistatic effects. Genet Mol Biol 35(4):802-809

Bocianowski J (2013) Epistasis interaction of QTL effects as a genetic parameter influencing estimation of the genetic additive effect. Genet Mol Biol 36(1):93-100

Bocianowski J, Krajewski P (2009) Comparison of the genetic additive effect estimators based on phenotypic observations and on molecular marker data. Euphytica 165:113-122 
Borràs-Gelonch G, Denti M, Thomas WTB, Romagosa I (2012) Genetic control of pre-heading phases in the Steptoe $\times$ Morex barley population under different conditions of photoperiod and temperature. Euphytica 183:303-321

Charmet G, Robert N, Perretant MR, Gaz G, Sourdille P, Groos C, Bernard S, Bernard M (1999) Marker-assisted recurrent selection for cumulative additive and interactive QTLs in recombinant inbred lines. Theor Appl Genet 99:1143-1148

da Silva Guimarães LM, de Resende MDV, Lau D, Rosse LN, Alves AA, Alfenas AC (2010) Genetic control of Eucalyptus urophylla and E. grandis resistance to canker caused by Chrysoporthe cubensis. Genet Mol Biol 33(3):525-531

Falconer DS (1981) Introduction to quantitative genetics, 2nd edn. Longman Press, New York

GenStat (2007) GenStat release 10 reference manual. Lawes Agricultural Trust, Rothamsted

Hayes PM, Liu BH, Knapp SJ, Chen F, Jones B, Blake T, Franckowiak J, Rasmusson D, Sorrells M, Ullrich SE, Wesenberg D, Kleinhofs A (1993) Quantitative trait locus effects and environmental interaction in a sample of North American barley germ plasm. Theor Appl Genet 87:392401

Imtiaz M, Ogbonnaya FC, Oman J, van Ginkel M (2008) Characterization of quantitative trait loci controlling genetic variation for preharvest sprouting in synthetic backcross-derived wheat lines. Genetics 178:1725-1736

Jannink JL, Jansen R (2001) Mapping epistatic quantitative trait loci with one-dimensional genome searches. Genetics 157:445-454

Jansen RC (1993) Interval mapping of multiple quantitative trait loci. Genetics 135:205-211

Kao CH, Zeng ZB, Teasdale RD (1999) Multiple interval mapping for quantitative trait loci. Genetics 152(3):12031216

Karakousis A, Barr AR, Kretschmer JM, Manning S, Jefferies SP, Chalmers KJ, Islam AKM, Langridge P (2003) Mapping and QTL analysis of the barley population Clipper $\times$ Sahara. Aust J Agric Res 54(12):1137-1140

Kleinhofs A, Kilian A, Saghai Maroof MA, Biyashev RM, Hayes P, Chen FQ, Lapitan N, Fenwick A, Blake TK, Kanazin V, Ananiev E, Dahleen L, Kudrna D, Bollonger J, Knapp SJ, Liu B, Sorrells M, Heun M, Franckowiak JD, Hoffman D, Skadsen R, Steffenson BJ (1993) A molecular, isozyme and morphological map of the barley (Hordeum vulgare) genome. Theor Appl Genet 86:705-712

Krajewski P, Bocianowski J, Gawłowska M, Kaczmarek Z, Pniewski T, Święcicki W, Wolko B (2012) QTL for yield componenets and protein content: a multienvironment study of two pea (Pisum sativum L.) populations. Euphytica 183:323-336

Lander ES, Botstein D (1989) Mapping Mendelian factors underlying quantitative traits using RFLP linkage maps. Genetics 121:185-199

Li ZK, Pinson SRM, Park WD, Paterson AH, Stansel JW (1997) Epistasis for three grain yield components in rice (Oryza sativa L.). Genetics 145:453-465

Liu T, Thalamuthu A, Liu JJ, Chen C, Wang Z, Wu R (2011) Asymptotic distribution for epistatic tests in case-control studies. Genomics 98(2):145-151

Ma W, Appels R, Bekes F, Larroque O, Morell MK, Gale KR (2005) Genetic characterisation of dough rheological properties in a wheat doubled haploid population: additive genetic effects and epistatic interactions. Theor Appl Genet 111:410-422

Ma XQ, Tang JH, Teng WT, Yan JB, Meng YJ, Li JS (2007) Epistatic interaction is an important genetic basis of grain yield and its components in maize. Mol Breed 20:41-51

Mao YC, London NR, Ma L, Dvorkin D, Da Y (2006) Detection of SNP epistasis effects of quantitative traits using an extended Kempthorne model. Physiol Genomics 28(1):46-52

Martinez O, Curnow RN (1994) Missing markers when estimating quantitative trait loci using regression mapping. Heredity 73:198-206

Mather K, Jinks JL (1982) Biometrical genetics, 3rd edn. Chapman and Hall, London

Melchinger AE, Piepho HP, Utz HF, Muminovic J, Wegenast TW, Torjek O, Altmann T, Kusterer B (2007) Genetic basis of heterosis for growth-related traits in Arabidopsis investigated by testcross progenies of near-isogenic lines reveals a significant role of epistasis. Genetics 177:1827-1837

Peng B, Li Y, Wang Y, Liu C, Liu Z, Tan W, Zhang Y, Wang D, Shi Y, Sun B, Song Y, Wang T, Li Y (2011) QTL analysis for yield components and kernel-related traits in maize across multi-environments. Theor Appl Genet 122:13051320

Pooni HS, Coombs DJ, Jinks PS (1987) Detection of epistasis and linkage of interacting genes in the presence of reciprocal differences. Heredity 58:257-266

Province MA (1999) Sequential methods of analysis for genome scan. In: Rao DC, Province MA (eds) Dissection of complex traits. Academic Press, San Diego, p 583

Rahman L, Khanam S, Roh JH, Koh HJ (2011) Mapping of QTLs involved in resistance to rice blast (Magnaporthe grisea) using Oryza minuta introgression lines. Czech J Genet Plant Breed 47(3):85-94

Romagosa I, Ullrich SE, Han F, Hayes PM (1996) Use of the additive main effects and multiplicative interaction model in QTL mapping for adaptation in barley. Theor Appl Genet 93:30-37

Rovaris SRS, de Araújo PM, Garbuglio DD, Prete CEC, Zago VS, da Silva LJF (2011) Estimates of genetic parameter in maize commercial variety IPR 114 at Paraná State. Brazil Acta Scientiarum Agronomy 33(4):621-625

Spickett SG, Thoday JM (1966) Regular response to selection. 3 Interaction between located polygenes. Genet Res 7:96-121

Tabanao DA, Bernardo R (2007) Multilocus epistasis, linkage, and genetic variance in breeding populations with few parents. Theor Appl Genet 115(3):335-342

Tinker NA, Mather DE, Rossnagel BG, Kasha KJ, Kleinhofs A, Hayes PM, Falk DE, Ferguson T, Shugar LP, Legge WG, Irvine RB, Choo TM, Briggs KG, Ullrich SE, Franckowiak JD, Blake TK, Graf RJ, Dofing SM, Saghai Maroof MA, Scoles GJ, Hoffman D, Dahleen LS, Kilian A, Chen F, Biyashev RM, Kudrna DA, Steffenson BJ (1996) Regions of the genome that affect agronomic performance in tworow barley. Crop Sci 36:1053-1062

Wang DL, Zhu J, Li ZK, Paterson AH (1999) Mapping QTLs with epistatic effects and QTL $\times$ environmental 
interactions by mixed linear model approaches. Theor Appl Genet 99:1255-1264

Yang J, Zhu J, Williams RW (2007) Mapping the genetic architecture of complex traits in experimental populations. Bioinformatics 23:1527-1536

Yi NJ, Shriner D, Banerjee S, Mehta T, Pomp D, Yandell BS (2007) An efficient Bayesian model selection approach for interacting quantitative trait loci models with many effects. Genetics 176(3):1865-1877
Yu SB, Li JX, Xu CG, Tan YF, Gao YJ, Li XH, Zhang Q, Saghai Maroof MA (1997) Importance of epistasis as the genetic basis of heterosis in an elite rice hybrid. Proc Natl Acad Sci USA 94:9226-9231

Zeng ZB (1994) Precision mapping of quantitative trait loci. Genetics 136:1457-1468 